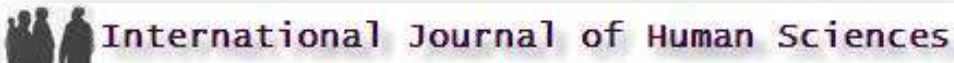

Volume: 11 Issue: 2 Year: 2014

\section{Effects of poverty on education}

\author{
Ronald Buck ${ }^{1}$ \\ Joe Deutsch ${ }^{2}$
}

\begin{abstract}
This article examines the effects of poverty on education. Many different aspects contribute to a community becoming impoverished such as deindustrialization, high unemployment rates, untreated mental health, and violent crimes. Impoverished communities rural and urban face many issues. These issues include dilapidated housing, lack of access to professional services, and most importantly inferior education. The education is inferior for a number of reasons; students are showing up to school with numerous problems that the teachers are unable to account for through instruction. The school facilities face structural inadequacies which have been proven to have an effect on the quality of instruction. The teachers in the schools, while qualified, are often times not supported by school administration. School administrators are busy with their own issues in determining what areas to allocate their limited budget. Poverty is a vast and complex issue that plagues communities in a seemingly endless cycle. However, working together to find effective ways of solving issues caused by poverty, the future can become a brighter for American youth growing up in poor communities.
\end{abstract}

Keywords: Poverty; Education; Teaching; Structural Inadequacies; Open Enrollment

\section{Introduction}

Poverty is defined as the state of being extremely poor (Bell, 1997). Large income deficiencies complicate the task of developing a sense of belonging and community in a given entity (O'Boyle, 2003). People in highly impoverished communities face a myriad of other deficiencies in meeting daily basic needs. As adults in the community, the burden of providing for their families becomes an ever daunting task because of limited mobility or access to meaningful employment (Wilton, 2003). The stress brought on by such conditions can contribute to mental health issues and affect decision making by the members of these communities. Social immobility and the passing of disadvantage through families is clearly linked to family background and personal skills (Mulford,

\footnotetext{
${ }^{1}$ Graduate Assistant, North Dakota State University, Health, Nutrition, \& Exercise Sciences, Ronald.Buck@ndsu.edu

2 Associate Professor of Physical Education, North Dakota State University., Health, Nutrition, \& Exercise Sciences joe.deutsch@ndsu.edu
} 
Buck, R., \& Deutsch, J. (2014). Effects of poverty on education. International Journal of Human Sciences, 11(2), 1139-1148. doi: $10.14687 /$ ijhs.v11i2.3043

Kendall, Ewington, Edmunds, \& Kendall, 2008). Other lifestyle issues can also arise from these conditions, including obesity (Deutsch \& Hetland, 2012). This evidence suggests that the cycle is likely to repeat itself as the next generation is born into similar circumstances.

"There is a consensus that education brings a range of returns (monetary and nonmonetary) that benefit both the person investing in the education and the community in which they live" (Stiglitz, Sen, Fitoussi, 2009, p.46). Attaining these returns is not as easy as it may sound, considering the effects of poverty on communities in regards to education. Regardless, educators and students alike work together every day in an attempt to gain access to these returns.

There are an overwhelming number of students attending schools in high-poverty communities who require support in multiple ways. Often times the teachers are at a loss on how to help meet students' needs (Mulford, et al., 2008). O’Donnell, Lambert, McCarthy, \& Christopher, (2008), found that a lack of qualified teachers entering the field is not the problem; instead the amount of quality teachers leaving the profession before retirement is the bigger concern. Retaining quality teachers should be a higher priority among administration. Unfortunately, principals in impoverished schools face other necessary issues directly related to the lack of a budget. Trying to retain highly qualified teachers who understand the social issues brought on by crippling poverty becomes a lower priority.

The schools in these communities are often facing structural inadequacies that contribute to the climate of the classroom environment (Uline \& Tschannen-Moran, 2008). This in turn, affects the quality of instruction. The culture of these schools in relation to teacher-student interactions is one of stress and lowered expectations and thus leads to a lack of student achievement. Negative teacher-student relationships and structural inadequacies affect the students' ability to learn and develop positive relationships with their local environment and superiors (O'Boyle, 2003; Van Maele \& Van Houtte, 2011).

There are many facets to running a successful school. Important pieces necessary to promote a successful school environment include student inclusion, engagement from the community, professional development, and securing funds for meaningful educational experiences. When principals seek to engage family and community members to align them with the mission and goals of the school, students perform better academically (Kirby \& DiPaola, 2011). Managing these facets in an effective manner is essential to running a successful school. However, the constant economic struggle finds its way from out in the community, through the school doors, and into the classrooms. 
Buck, R., \& Deutsch, J. (2014). Effects of poverty on education. International Journal of Human Sciences, 11(2), 1139-1148. doi: $10.14687 /$ ijhs.v11i2.3043

\section{The Communities Impact on Poverty}

A community is a group of people living in the same place or having a particular characteristic in common (Bell, 1997). With some communities a common characteristic people share is earning an income that is at or below the federal poverty line. Some of the factors that contribute to people entering poverty and remaining in poverty have to be examined to gain a deeper understanding. These factors include but are not limited to social immobility, concentration of poverty, stressful living conditions, poor education, and a lack of opportunities to exit poverty.

Social immobility is the inability of an individual to branch out and develop new social networks helping the chances of improving ones socioeconomic status. Living in impoverished communities have grave implications for peoples' health, education, and social relations. Without access to a motor vehicle or affordable transportation, the potential for building social relationships is severely constrained (Wilton, 2003). The effects of this hindrance expands beyond the individual because there becomes a lack of meeting new people which contributes to missed opportunities to help others and engage in meaningful social activities. Some meaningful social activities include, exercise, hanging out with friends, or enjoying a coffee. It becomes difficult to deal with everyday life when one is unable to engage in enrichment or leisure activities. As the concentration of affluence and poverty become more apparent, conditions have seemingly gotten worse for the individuals who live in impoverished communities (Wilton, 2003).

Merely working to exist is a struggle that many adults face when living in poverty. The concentration of poverty has exacerbated the toll taken on the families who cannot move out of such conditions. In the early development of the United States (U.S.) it was necessary for the poor and affluent to interact due to the constraints of the time. However, the advancements of transportation, communication, and construction has led to a new understanding of living. This understanding is that one could separate work life form home life. Meanwhile, the poor could not afford better transportation or better housing and remained in their living conditions.

From a historical perspective, the economy of the U.S. has been constructed to rely on a readily available low wage work force, starting with indentured servitude and slavery. This doesn't even begin to touch the surface of the classification of race and how those effects play out in today's society. This structure opened the door for mass outsourcing of manufacturing jobs also known as deindustrialization, and replacing these jobs with menial service jobs that pay low wages (Yanagisawa, 2011). Meanwhile, the cost of living rises with each passing year. Issues such as violent crimes, teen pregnancy, underachieving schools, stagnant economic development, and dilapidated housing all contribute to the living conditions of impoverished communities. Many 
Buck, R., \& Deutsch, J. (2014). Effects of poverty on education. International Journal of Human Sciences, 11(2), 1139-1148. doi: $10.14687 /$ ijhs.v11i2.3043

Americans attribute the inability to exit poverty to personal choice and individual failures, but neglect to factor in systemic inequities.

Attributing the failure to succeed and reach life benchmarks does little help people living in poverty. This line of thinking simply deescalates into blaming poor people for being poor. Leventhal and Brooks-Gunn (2003) revealed that parents who moved to low-poverty neighborhoods reported significantly less distress than parents who remained in high-poverty neighborhoods. With less stressful living conditions, one is able to think more clearly and has time to plan. Since humans are constantly taking in sensory information, it is safe to conclude that children are also affected by their living conditions. Research has stressed the importance of education in providing the skills and abilities that underpin economic production that can lead to a better quality of life (Leventhal \& Brook-Gunn, 2003). If the schools in one's area have a high dropout rate or low standardized test scores, what options are available for students to attain the education level necessary to influence their quality of life? By recognizing the lack of knowledge and skills to take advantage of opportunities, a link between being born into poverty and failing to exit poverty as an adult could be exposed. In recent years, other options have surfaced as a way to provide kids living in poverty with quality education opportunities.

Charter schools have become a viable option, open enrollment is possible, and magnet schools provide opportunities for students to go to better schools. These options however, do not address the systemic issues that contribute to the local underachieving public schools. Charter schools serve as their own school district and secure sources of funding other than federal and state tax dollars to function. Since charter schools work as their own school district, they have the power to be more selective with their enrollment and are able implement different styles of education which can in many cases be highly effective. Open Enrollment allows for students in one district to attend school in a completely new district as long as they can provide their own transportation. Since large metro areas have vast public transportation systems, this becomes a way to attend a school with better facilities, and an opportunity to engage in a different learning atmosphere. Magnet schools are schools that offer programs to students who want to specialize in subjects such as arts and media or math and science when such programs are not offered at the school nearest their home.

The systemic issues contributing to failing local public schools include deindustrialization, and the erosion of the economic status of a given area. It is important to note that urban centers formed around places with a high number of jobs and fairly cheap living conditions. It was sustainable until business practices allowed for jobs to be cut or outsourced at an alarming rate. This forced a high number of families to become unstable fragmenting neighborhoods causing high stress between the people who live there. The inability for these areas to recover caused the stagnant economic 
Buck, R., \& Deutsch, J. (2014). Effects of poverty on education. International Journal of Human Sciences, 11(2), 1139-1148. doi: $10.14687 /$ ijhs.v11i2.3043

development which led poverty abound. Budget cuts force administrators and school board members to cut nonessential staff and programming which could help enrich the students' educational experience and thus the cycle of a failing school begins.

\section{The Public Schools Impact on Poverty}

A school is an institution for giving children instruction. Schools in all communities deserve the bare essentials when it comes to education, highly qualified teachers, current textbooks, and safe and adequate facilities (Powers, 2004). Schools have the ability to be the pride and joy of a community. When ran in a successful manner, schools contribute to the success of the community. In poor communities however, funding is an issue which crosses over into the students' and teachers' attitudes towards education. This can lead one to believe that students are being left behind due to a macro-level failure, which influences micro-level behavior (Yanagisawa, 2011).

Uline and Tschannen-Moran (2008) examined the link between school climate and poor academic achievement. The main factors in the study were the conditions of school facilities and the inability to keep up with the increase in school populations. According to Uline \& Tschannen-Moran (2008), examining student achievement scores showed a difference between five and 17 percentage points between students learning in inadequate buildings and students learning in functional buildings. When controlled for factors such as socioeconomic status, building conditions is a major indicator of student performance (Uline \& Tschannen-Moran, 2008). When there is no money being allocated toward educational facilities, schools cannot be updated. The problems of poverty described previously shows that growing up poor has grossly adverse effects on the human mind and future living conditions. Growing up poor cuts the amount of opportunities one would have had to be prepared for life's hardships by immense proportions. Further indicators examined for student achievement is the quality of teachers in the building.

\section{Teachers}

Having highly qualified teachers is very important because they possess the ability to relate to every student in their classroom. The teachers in high poverty communities have many obstacles to overcome in order to be successful (Mulford et. al, 2008). Some of the obstacles teachers face includes building trusting relationships, lack of updated textbooks, and teaching students whose basic needs are not being met outside of the classroom. Finding a way to relate to every student is not always easy, but effective teachers find ways to make the classroom environment welcoming and successful (Vickers \& Hale, 2010). Curriculums and programs are also often introduced with a mission of fostering a healthier student by providing quality resources and professional development for these teachers (Deutsch \& Christianson, 2014). 
Buck, R., \& Deutsch, J. (2014). Effects of poverty on education. International Journal of Human Sciences, 11(2), 1139-1148. doi: $10.14687 /$ ijhs.v11i2.3043

Many times in interactions between students and school staff, there is a cultural breakdown in communication. This leads to loss of control of the situation forcing the student to possibly face suspension. When suspension is added to an already high number of absences, this causes the student to miss many class periods. There is something to be said about the teacher-student relationship and the trust that has to be developed. When students believe that their teachers trust them to do the right thing, they often times reach those expectations and feel more engaged during the school day. When the teacher's expectations of students are low, evidence suggests that they are not given a fair chance at a quality education (Van Maele \& Van Houtte, 2011). Although trusting the students may be difficult based on previous behaviors, procedures and routines can be established in order to teach the students the proper expectations.

Beginning teachers often find themselves not responsible for workplace conditions and attribute student failures to their own personal short coming. Expert teachers however, find ways to include everybody and plan for diverse populations (Vickers \& Hale, 2010). Since retaining highly qualified teachers is a tough task for poor schools, the students in the community are then left with average teachers in below average working conditions. Below average working conditions affect the motivation and mindset of the employee. In the case of teachers, motivation has an effect on the quality of education being received by the students as noted by test scores (Uline, TschannenMoran, 2008).

Since teacher education programs often times do a poor job in conveying the knowledge and understanding necessary to teach multicultural and diverse populations, teachers are being sent into classrooms underprepared to teach a good percentage of their students (Wasonga, 2005). When students become school aged, parents have an understanding that the teachers will be able to teach their students the necessary skills to be academically successful, thus opening doors of opportunity. This cannot happen if the teachers are not prepared to mitigate the effects that come with growing up in poverty. It is also important to note that teachers have a hard time teaching structure to children who have limited structure at home. When combining these two issues, the main person who loses is the child. Many teachers are unable to account for the needs that a high percentage of their students bring into the classroom and causes them to leave the profession prematurely (Mulford, et al., 2008).

Since impoverished schools are usually in dangerous or perceived to be dangerous neighborhoods, the teachers in the building may also feel that tension. That perceived tension can affect their decision making skills causing instruction to falter. Teachers have become increasingly Caucasian, middle class, and female, despite changing demographics in education (Wasonga, 2005). This fact compounded with the beliefs and perceptions of impoverished communities play a role in how well 
Buck, R., \& Deutsch, J. (2014). Effects of poverty on education. International Journal of Human Sciences, 11(2), 1139-1148. doi: $10.14687 /$ ijhs.v11i2.3043

one is able to teach. The media's role in shaping the opinions and beliefs about poor communities has far worse implications for the people living in impoverished communities than those who don't. These misguided beliefs and opinions are then brought into the schools by the teachers, students, and administration and a self-fulfilling prophecy is created.

\section{Students}

The students in impoverished schools often times lack self-efficacy. Financial struggles often lead to psychological struggles which affect daily choices and decision making skills (Yanagisawa, 2011). When students go home they may be in a place where they do not feel safe. Basic physiological needs should be met in order for learning and motivation to occur according to Maslow's hierarchy of needs (Wilson \& Madsen, 2008). Another factor contributing to impoverished students falling behind their wealthy counterparts is the availability of enrichment summer programs. Impoverished schools face many difficulties in preparing their students for success beyond high school. Some of the difficulties fall on the shoulders of the students while other difficulties are out of their control.

When students go home, they may be exposed to some type of abuse, whether it is physical, verbal, or sexual. These forms of abuse can also occur at school, leaving a student in a no-win situation. The high caseload of counselors and other mental health practitioners in impoverished communities affects their quality of work (Yanagisawa, 2011). This affects the students who need the expertise but are unable to receive quality care because they cannot afford better services. However, an emphasis on correcting individuals only addresses part of the problem and does not address the larger societal issues. Impoverished communities are impoverished for a reason, there are little to no material resources, high rates of unemployment, and overall stressful living conditions (Wilton, 2003). Students living in these communities suffer from the same things that affect their parents. Much of their free time, including summers, may be devoted to working to help support the household or spent abusing drugs and alcohol as an escape from the pressures in their lives. This reality leaves very little room for interest in summer enrichment programs. This is concerning because as children grow, their overall psychomotor capacity will increase (Luce \& Deutsch, 2014), but they need education to develop it. Along with the psychomotor development, their gross motor development is lacking without the physical education classroom providing an important setting for students to learn healthy activities that can be participated in over the course of a lifetime (Myrum, Deutsch, \& Christianson, 2012).

The summer learning loss that occurs among students more significantly affects students in a lower socioeconomic status (SES) (Green, Lewis, Kent, Feldman, Motley, Baggett, \& Lewis, 2011). The summer learning gap is an extension of the shortcomings in kids who grow up in impoverished 
Buck, R., \& Deutsch, J. (2014). Effects of poverty on education. International Journal of Human Sciences, 11(2), 1139-1148. doi: $10.14687 /$ ijhs.v11i2.3043

neighborhoods. In order to combat this, initiatives are needed to provide summer enrichment opportunities for students living in poverty. An opportunity was provided by Green his research team which provided a summer enrichment program. The results indicated that the students who participated in the program experienced little to no loss in learning giving them a step ahead of other students at their school.

When one family experiences generational poverty it is no surprise they are underachieving by societal standards. Lack of educational opportunities, joblessness, and undiagnosed mental illness are just a few of the issues faced by families living in poverty. This reiterates that disadvantage is passed through generations (Mulford et al., 2008). A feeling of inadequacy and failure is a feeling that too many students feel, and once they become adults, those feelings do not simply disappear. In order to address these issues, people would have to understand what caused them in the first place. These issues can be addressed, but need to be handled strategically.

\section{Addressing the Issues}

It is important to remember that poverty involves the lives of people. It is not an abstract force that plagues people rendering them incapable of escaping it. The difficulty in addressing all of the issues caused by poverty would be too much for any community to handle, so prioritizing what needs to be addressed could be an effective way to handle the situation. This way less important issues may be dealt with indirectly as a result of taking care of more major problems. Addressing the educational setbacks caused by poverty will be an ongoing task for school administrators. Many major problems can be addressed by promoting a positive school environment, strong leadership, engagement from the community (Kirby \& DiPaola, 2011), as well as securing funds. With these four issues being addressed, it can help mitigate the stressful day-to-day conditions which contribute to making the school environment an unsuccessful one.

Things necessary for a positive school environment include clear expectations, supportive structures and services, and positive leadership (Mulford et al., 2008). With clear expectations, building staff and students understand what the boundaries are and are held accountable if they don't follow protocols. This builds an environment that becomes self-regulating because everybody is invested in upholding the expectations. Supportive structures and services such as teacher development and social skills for students help teach the correct behaviors on how to deal with situations that arise during the school day. If integrated into the curriculum teachers begin to become mindful of how their words and actions are perceived by students. Additionally, students will begin to understand why they are at school in the first place. Positive leadership shows that the principals and administrators are committed to persevere through times of adversity such as not making Adequate Yearly Progress (AYP) or school wide behavior issues. Seeing that type of 
Buck, R., \& Deutsch, J. (2014). Effects of poverty on education. International Journal of Human Sciences, 11(2), 1139-1148. doi: $10.14687 /$ ijhs.v11i2.3043

commitment can motivate others to believe in what the administration is trying to accomplish through establishing a positive school environment.

Although establishing a positive environment within a school is a challenging task, it is just as important to recognize what makes the environment of the community positive. Principals who were able to align school goals and community goals had better success within the school (Mulford, et al., 2008). Community involvement is one of the major factors that benefits a schools success. When the teachers and members of the community believe that their students can succeed despite struggling with poverty, the students are more likely to achieve at higher levels. When the community becomes involved, people have a vested interest in making sure that their children are getting the services they need to be successful. It takes a collective mindset to positively influence the students in impoverished schools (Kirby \& DiPaola, 2011). Without community involvement, the actions of the students, teachers, and administration are left unchecked. Since school funding comes from the local tax base, people should feel more invested in the schools of their community. When employment becomes nonexistent, the academic performance of the student may suffer due to heightened levels of stress.

Securing educational funds is necessary for a successful school environment, but there are many different avenues to explore to secure them. The use of grant writers and the proper use of tax dollars could help fund educational opportunities for the students. States that relied more heavily on local revenues showed an inequitable distribution of educational funding (Moser \& Rubenstein, 2002). Most people just want to be able to go to work and earn a decent living. This cannot happen if there is a lack of employment opportunities and a lack of social mobility (Wilton, 2003). With more ways to earn money, the schools can begin to allocate such money towards various areas. Areas include updated facilities, better school supplies, and quality teachers which can help improve the academic performance of the students (Powers, 2004). While funds are being secured, the support of the community could be the backbone for ensuring that the money is going where it needs to. The students deserve the best possible educational opportunities, but it cannot happen if the budget is underfunded every year.

Poverty is something that is inherent in society as long as money is involved, but the people living in poverty should have better opportunities to exit. The way people living in poverty are viewed affects how they are able to live. Due to the increasing wealth gap, more students are born into poverty than ever before. Without the proper structures in place and the proper mentality of the general public and elected officials, inequality will persist. This can be avoided if the proper measures are taken now and we start investing in our future with our time, resources, and understanding. 
Buck, R., \& Deutsch, J. (2014). Effects of poverty on education. International Journal of Human Sciences, 11(2), 1139-1148. doi: $10.14687 /$ ijhs.v11i2.3043

\section{References}

Bell, M. (1997). The development of expertise. Journal of Physical Education, Recreation, and Dance, 68(2), 34-38.

Deutsch, J., \& Christianson, P. (2104). Physical best and fitnessgram use among United States PETE programs. Asian Journal of Physical Education and Recreation, 20(1), 6-11.

Deutsch, J., \& Hetland, K. (2012). The impact of music on PACER test performance, enjoyment and workload. Asian Journal of Physical Education and Recreation, 18(1), 6-14.

Green, A., Kent, A., Lewis, J., Feldman, P., Motley, M., Baggett, P., \& Simpson, J. (2011). Experiences of elementary pre-service teachers in an urban summer enrichment program. Western Journal of Black Studies, 35(4), 227-239.

Kirby, M., \& DiPaola, M. (2011). Academic optimism and community engagement in urban schools. Journal of Educational Administration, 49(5), 542-562.

Leventhal, T., \& Brooks-Gunn, J. (2003). Moving to opportunity: An experimental study of neighborhood effects on mental health. American Journal of Public Health, 93(9), 1576-82.

Luce, K., \& Deutsch, J. (2014). How to run an academy season for youth soccer. The Journal of Youth Sports, 7(2), 24-27.

Moser, M., \& Rubenstein, R. (2002). The equality of public school district funding in the United States: A national status report. Public Administration Review, 62(1), 63-72.

Mulford, B., Kendall, D., Ewington, J., Edmunds, B., Kendall, L., \& Silins, H. (2008). Successful principalship of high-performance schools in high-poverty communities. Journal of Educational Administration, 46(4), 461-480.

Myrum, R., Deutsch, J., \& Christianson, P. (2012). The effect of technology on physical education classroom. Asian Journal of Physical Education and Recreation, 18(2), 33-40.

O'Boyle, E., (2003). Income gap between poor families and others: Signs of individual freedom or proof of social inequality? Forum for Social Economics, 32(2), 57-65.

O'Donnell, M., Lambert, R., \& McCarthy, C. (2008). School poverty status, time of year, and elementary teachers' perceptions of stress. The Journal of Educational Research, 102(2), 152160.

Powers, J. (2004). High-stakes accountability and equity: Using evidence from California's public schools accountability act to address the issues in Williams v. state of California. American Educational Research Journal, 41(4), 763-795.

Stiglitz, J., Sen, A., \& Fitoussi, J. (2009), Report by the commission on the measurement of economic performance and social progress. Commission on the Measurement of Economic Performance and Social Progress, Paris

Uline, C., \& Tschannen-Moran, M. (2008). The walls speak: The interplay of quality facilities, school climate, and student achievement. Journal of Educational Administration, 46(1), 55-73.

Van Maele, D., \& Van Houtte, M. (2011). The quality of school life: Teacher-student trust relationships and the organizational school context. Social Indicators Research, 100(1), 85-100.

Vickers, B., \& Hale, B., (2010). Perceptions of self-development throughout the spectrum of football coaching expertise. Journal of Coaching Education. 3(3), 117-141.

Wasonga, T. A. (2005). Multicultural education knowledgebase, attitudes and preparedness for diversity. The International Journal of Educational Management, 19(1), 67-74.

Wilson, I., \& Madsen, S. R. (2008). The influence of Maslow's humanistic views on an employee's motivation to learn. Journal of Applied Management and Entrepreneurship, 13(2), 46-62.

Wilton, R. D. (2003). Poverty and mental health: A qualitative study of residential care facility tenants. Community Mental Health Journal, 39(2), 139-56.

Yanagisawa, A. (2011). Poverty: Social control over our labor force. International Journal of Social Economics, 38(4), 316-329. 